Cytologia 43: 187-196, 1978

\title{
Karyological Characteristics of Cricotopus algarum Kieffer (Diptera, Chironomidae)
}

\author{
Paraskeva Michailova \\ Institute of Zoology, Academy of Sciences, Ruski 1, Sofia, Bulgaria
}

Received July 19, 1976

Most of the karyological investigations are on the species of subfamily Chironomidae. The species of subfamily Orthocladiinae are not so well studied. We have karyological data only about Cricotopus vitripennis and $C r$. varians and some species of Cr. gr. silvestris (Beermann 1952, Michailova 1975, 1976). The external morphological similarity of the species of this subfamily is a hindrance for its systematics and causes some contrary opinions in the literature concerning some genera and some species (Hirvenoja 1973). Many of the species are incorporated in groups. The combination of the external morphological with the karyological methods will serve the taxonomical diagnostics of the species of this subfamily.

The species $\mathrm{Cr}$. algarum belongs to the "fuscus" group, which incorporates three species (Hirvenoja 1973). The implementation of the anatomical and the morphological methods is not sufficient to distinguish the species of this group. That is why the aim of this study was the karyological analysis of Cricotopus algarum with a detailed description of the chromosomes, which enabled the species determination even in the larval stage. The chromosomal polymorphism was traced during a period of two years.

\section{Material and methods}

The material (IV age group larvae) was collected from the stone surface in the lake of Durankulak in Spring in 1973 and 1974. To have better precision we raised adults in the laboratory and determined them according to Hirvenoja, 1973. Combining the external with the karyological data, we proved that it was the species Cr. algarum. The fixation of the material, the karyological analysis, the identifying of the chromosomes and the statistics were done by means of the method described by Valkanov and Michailova (1974). To measure the length of the chromosomes we selected nuclei with equal degree of polytene of the chromosomes. Every chromosome is divided into left and right arms by its centromere. Every arm was measured, the ratio of the long and the short arms was calculated by means of the table of Levan, Fredga, Sandberg, (1964), and the form of the chromosomes was determined. Sixtyseven larvae were analyzed karyologically using preparations of chromosomes of the salivary and the sex glands. The chromosome aberrations were established by means of the comparison with the standard map. We indicated the number of the chromosome and the point of the aberration. The aberrations of the females are marked with one asterisk and those of the males with two asterisks. 
We made statistical analysis to determine the polymorphism of the individuals for the distinct years (Lakin 1973). The method of $\chi^{2}$ was used to determine the sex ratio.

Chromosomes without aberrations were used to make the chromosome map. The dividing of the chromosomes into several parts was done arbitrarily, using bands as markers of the chromosomes.

\section{Results and discussions}

The diploid set consisits of $2 n=6$ chromosomes. " $B$ " and heterochromosomes were not established. The first pair of chromosomes was submetacentric $L / R=1,94$; the second was metacentric $L / R=1,68$ and the third was acrocentric (Table 1). Significant difference between the length of the chromosomes was established. Similarly to the other chironomids, in this case an intensively heterochromatic band with a diameter bigger than that of the chromosome was accepted to be the centromere region of the polytene chromosomes. A typical peculiarity of the karyotype was the complete homologous pairing. Another peculiarity was the presence of a chromocentre, which was first observed in the genus Cricotopus.

Table 1. Length of the chromosomes and correlation of their arms in

Cricotopus algarum

\begin{tabular}{|c|c|c|c|c|c|c|c|c|c|c|}
\hline Chromosome & $\mathbf{n}$ & $\mathrm{x} \pm \mathrm{m}$ & $\sigma$ & $d$ & $m_{d}$ & $t_{d}$ & $\mathbf{P}$ & $\mathrm{L}$ & $\mathbf{R}$ & $\mathbf{L} / \mathbf{R}$ \\
\hline I & 30 & $\begin{array}{c}418,0 \pm \\
8,39\end{array}$ & 45,96 & - & $\longrightarrow$ & - & - & $\begin{array}{c}276,0 \pm \\
8,03\end{array}$ & $\begin{array}{c}142,0 \pm \\
11,0\end{array}$ & 1,94 \\
\hline II & 30 & $\begin{array}{c}351,7 \pm \\
7,79\end{array}$ & 42,68 & $\mathbf{M}_{1}-\mathrm{M}_{2}=66,3$ & 11,45 & 5,76 & 0,001 & $\begin{array}{c}220,3 \pm \\
3,34\end{array}$ & $\begin{array}{c}131,3 \pm \\
4,25\end{array}$ & 1,68 \\
\hline III & 30 & $\begin{array}{c}194,0 \pm \\
4,41\end{array}$ & 24,15 & $\begin{array}{l}M_{2}-M_{3}=157,7 \\
M_{1}-M_{3}=22,4\end{array}$ & $\begin{array}{l}8,85 \\
9,48\end{array}$ & $\begin{array}{l}17,6 \\
23,6\end{array}$ & $\begin{array}{l}0,001 \\
0,001\end{array}$ & & & \\
\hline
\end{tabular}

1. Description of the chromosomes

The first chromosome: it is divided into 32 parts. The left arm begins with expansion, containing several light-coloured bands. Next follow heterochromatic bands; the zone between 1 and $1 / 2$ has a little expansion, containing a light-coloured band. There is one euchromatic band between two heterochromatic bands in part $1 / 2$. Next follow several euchromatic bands; there are three dark bands in section $2 / 3$, but they are not seen well in some cases. In section $3 / 4$ there is a little embarrassment, containing a very dark band, followed by two heterochromatic bands. The bands in section $4 / 5$ are also used to identify the chromosome. Some individuals have granulated bands before part 5/6 and some others do not have well expressed bands. Before part 5/6 there are three dark bands. They are followed by two light-coloured and two dark bands in part 6/7. There is a little expansion and a dark band in part 7/8. Two almost combined heterochromatic bands in part are used for the identification. The bands after $8 / 9$ are not always well expressed. Sometimes they are too much heterochromatic and sometimes the bands of only one of the homologues are heterochromatic. Two dark bands in 


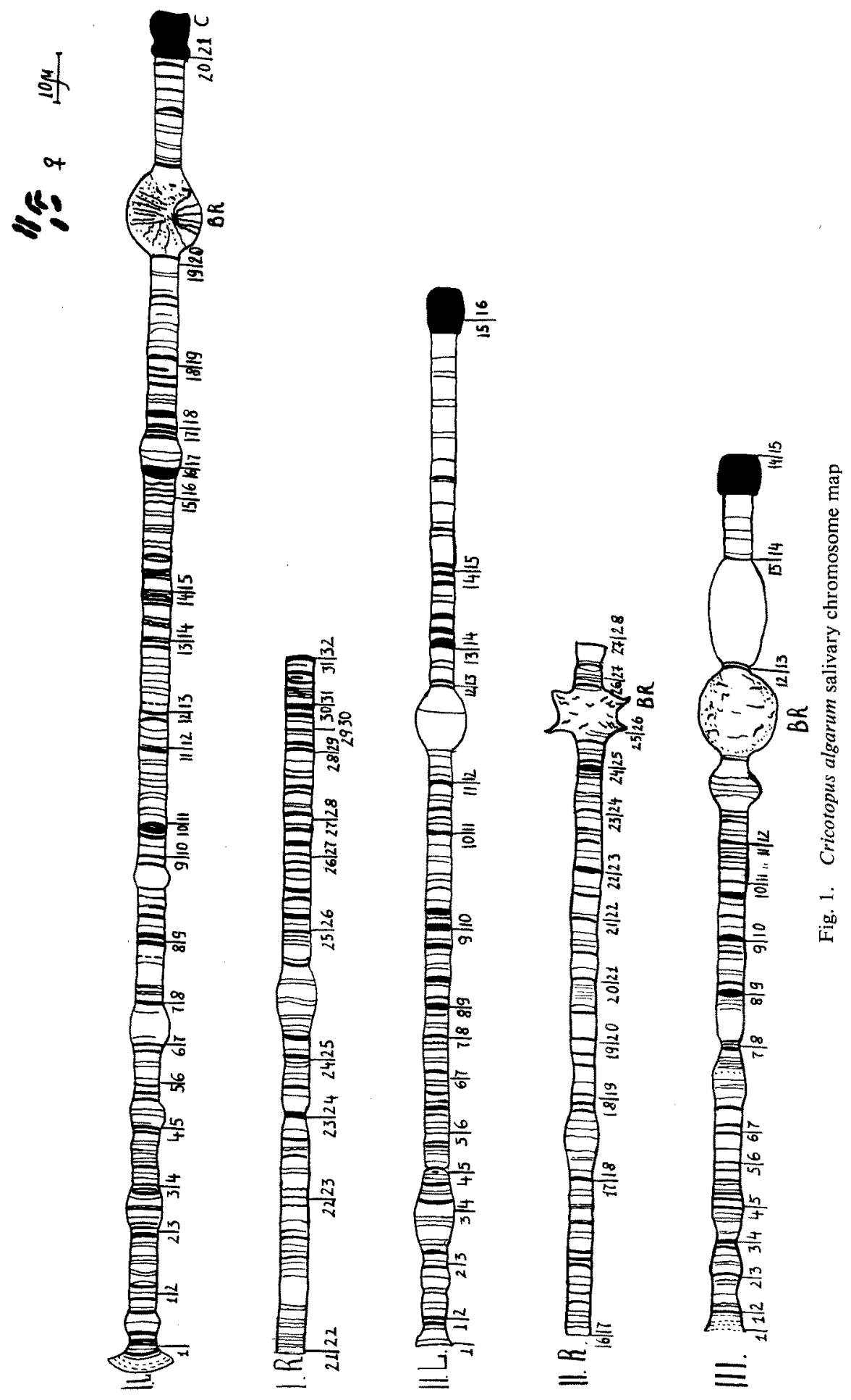


section 9/10 are used as markers of this arm of the chromosome. The dark bands in sections 10/11, 11/12 and 12/13 are typical also. A light-coloured part follows; some individuals have three couples of heterochromatic bands before section $14 / 15$ and the bands of some other individuals are incorporated in two groups of three bands in every one. There are seven light-coloured bands before the heterochromatic bands of section $15 / 16$. Sections $16 / 17$ and $17 / 18$ contain intensively heterochromatic bands. They are separated one from another by euchromatic bands, located in a little expansion. There are euchromatic bands by the Balbian ring, located after section 19/20, but they are not well expressed in all individuals. There is a centromere section in part 20/21. An alternation of light-colorued and dark bands can be seen by section 22/23. Most of the individuals have homozygous inversion in section $22 / 23$, combined with an incomplete homologous pairing. An

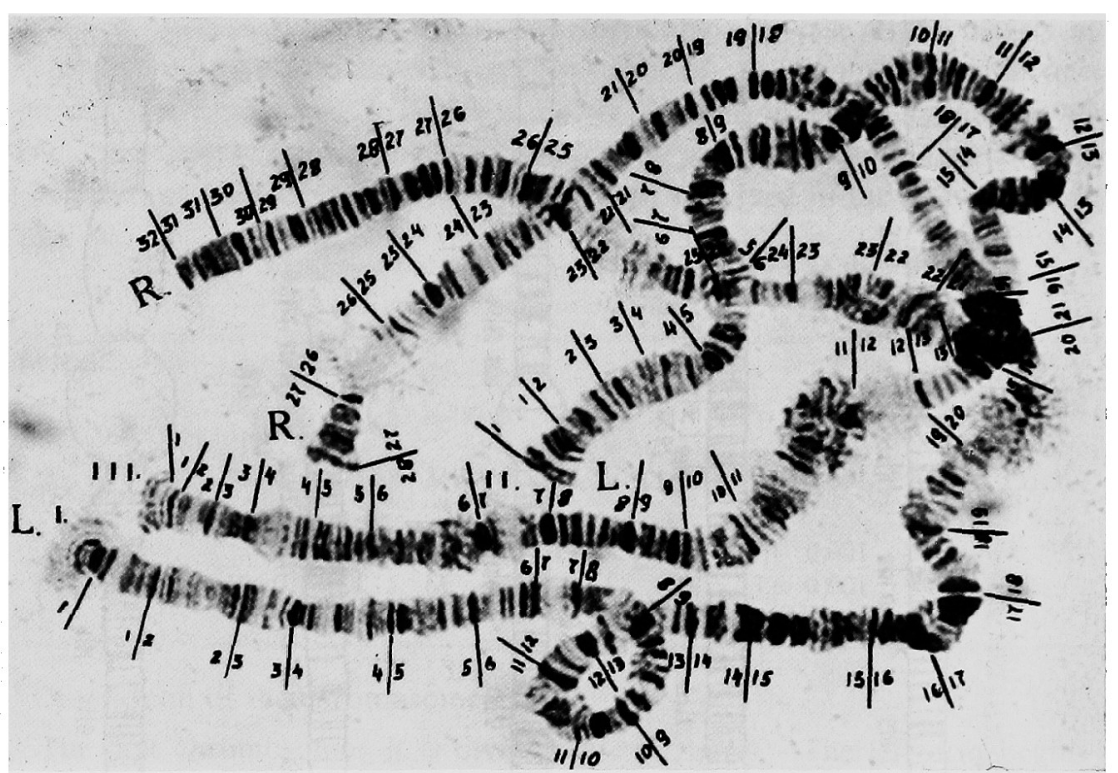

Fig. 2. Salivary chromosomes of Cricotopus algarum.

intensivelly heterochromatic band is contained in an embarrassment in section $23 / 24$. The expansion between $24 / 25$ and $26 / 25$ is typical for this arm. Very intensively heterochromatic bands can be seen after section $25 / 26$ and till the end of the chromosome; from $25 / 26$ to $26 / 27$ every heterochromatic band is separated from the next one by an euchromatic band. The four dark bands of section 26/27 are also markers of this arm. There is a light-coloured band between two heterochromatic bands in section $27 / 28$. A comparatively dark zone, containing several combined euchromatic bands can be seen between sections $30 / 31$ and 31/32. The end of the chromosome (section 31/32) has two dark bands, separated by euchromatic bands (Fig. 1 and Fig. 2).

The second chromosome. It is divided conditionally into 28 sections. The left arm of this chromosome begins with a little expansion; it contains two not very 
dark bands. It is followed by a light-coloured part and by the typical heterochromatic bands in section $1 / 2$. There is a little embarrassment between sections $1 / 2$ and $2 / 3$; there is an euchromatic band between two heterochromatic bands in section $2 / 3$. Next follows a part, containing euchromatic bands. Two heterochromatic enclose several euchromatic bands in a section after 3/4. An embarrassment, containing a heterochromatic band can be seen in section 4/5. Two light-coloured and two intensively heterochromatic bands follow. The heterochromatic band in section $7 / 8$ and the granulated band before it are used to identify this arm of the chromosome. The intensivelly heterochromatic band in section $8 / 9$ is enclosed by two light-coloured bands. A light-coloured and a dark band follow; in section $9 / 10$ three dark bands are separated by euchromatic bands. By section $10 / 11$ there is a part, containing light-coloured bands and an incomplete homologous pairing can be seen here in most of the cases. Two light-coloured bands are located between two heterochromatic bands in section $10 / 11$. There is a dark band between two euchromatic bands in section 11/12. An expansion, enclosed by two heterochromatic bands follows. A series of dark bands begins from section 13/14. A part, containing euchromatic bands seen differently in the individuals, is located between section $14 / 15$ and the centromere. Section 16/17 contains several euchromatic bands. Heterochromatic bands in section $18 / 19$ are used to identify this arm of the chromosome. Interrupted, light-coloured bands in section $18 / 19$ can be seen in some of the individuals and in some others those bands are looking like "waves". The intensively heterochromatic bands in section 19/20 are typical. The heterochromatic bands in sections $20 / 21,21 / 22$, are separated by euchromatic bands. The heterochromatic band in section $22 / 23$ is typical for the right arm of the chromosome. The part after $24 / 25$, containing a dark band, enclosed by two euchromatic bands is permanent for all individuals. The Balbian ring after section 25/26 is also used for the identification of this arm of the chromosome. The euchromatic bands in section $26 / 27$ are characteristic. The chromosome ends with a heterochromatic band in section $27 / 28$ (Fig. 1 and Fig. 2).

The third chromosome. It is divided into 15 sections. The chromosome begins with several euchromatic bands. The heterochromatic bands in sections $1 / 2$ and $2 / 3$ enclose a zone, containing several euchromatic bands. The two heterochromatic bands in section $3 / 4$ are typical for the chromosome. Only some of the individuals have an expansion after this section. There are two couples of dark bands in section $4 / 5$. Two euchromatic bands are following; section $5 / 6$ contains three heterochromatic bands. Some individuals have expansions on the two sides of the dark bands in section 7/8. The bands in sections $8 / 9,9 / 10$ and $10 / 11$ are used as markers of the chromosome. Some of those heterochromatic bands are results of the combinations of two bands. A part with euchromatic bands follows. The Balbian ring is located in section $12 / 13$ and it is separated by a heterochromatic band. A puff, located immediatelly after the Balbian ring and separated with a dark band can be seen in some of the individuals. In the cases, when the puff is missing, the separating band is euchromatic. This is an example of a well expressed position effect. The centromere section of the chromosome is located in part $14 / 15$. 
2. Chromosomal polymorphism

The chromosomal polymorphism provides the adaptation of the population towards the permanently changing conditions of the environment (Da Cunha 1955, Chubareva 1974). The analysis of the chromosomal polymorphism of Cr. algarum presented 9 types of aberrations: 2 types of paracentric heterozygous inversions, 2 types of duplications, 4 types of homozygous inversions and 1 type of deletion.

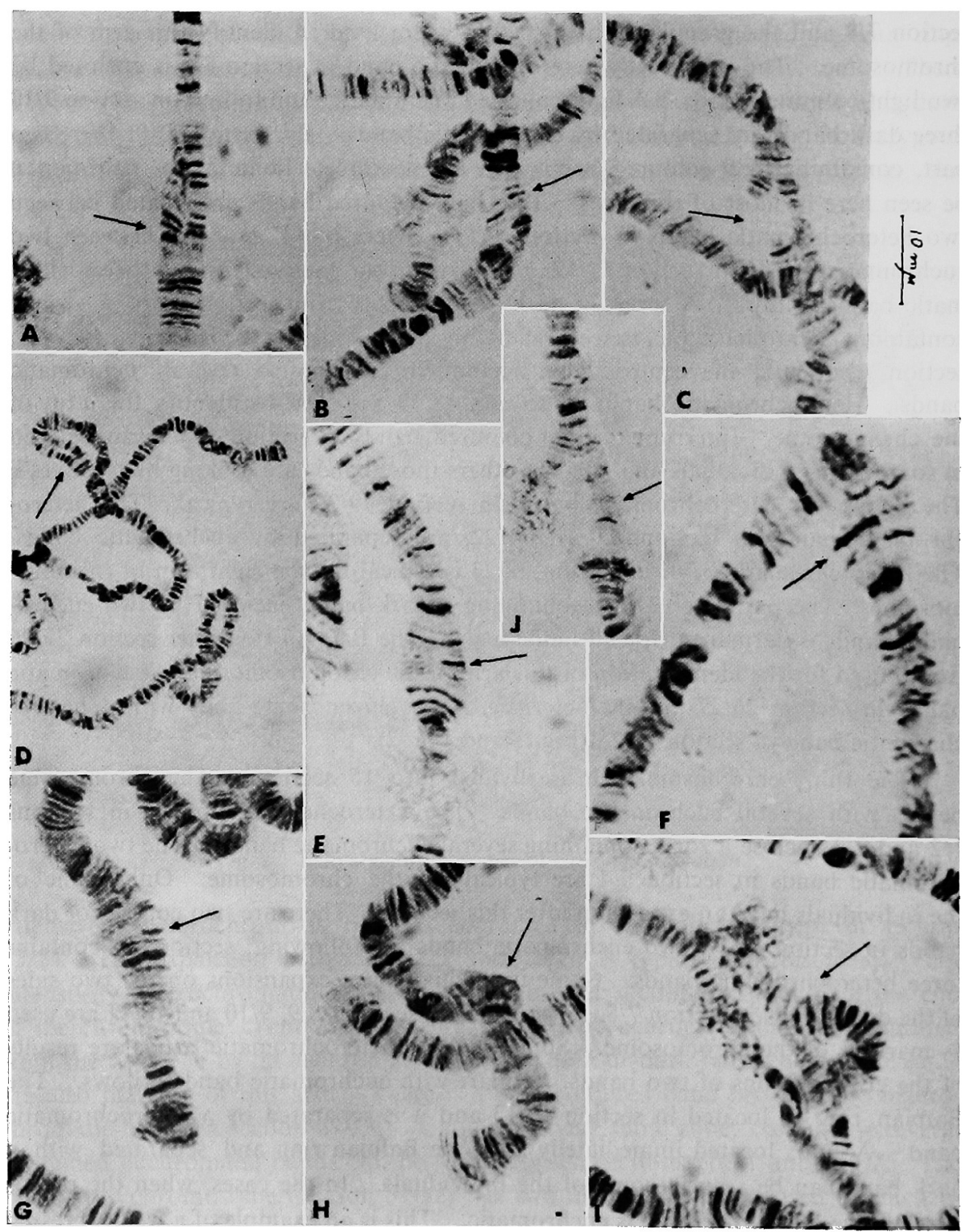

Fig. 3. Aberrations and their localization. a, Hom. Inv. 9/10. b, Hom. Inv. 23/24. c, deletion 10/11-11/12. d, duplication 1/2-2/3. e, microduplication 23/24. f, Hom. Inv. 22/23. g, Hom. Inv. 23/24. h, Het. Inv. after 3/4. i, Het. Inv. 9/10. j, Het. Balbian ring. 
The exact localization and the frequency of occurrence of the aberrations are presented by Table 2. The females are more polymorphous. It is clear from the table, that the aberrations of this species can be divided into two groups.

1. Repeatedly occurring aberrations: the microduplication in the second chromosome (Fig. 3e), the heterozygous inversion in the same chromosome (Fig. 3h) and the complex heterozygous inversion in the third chromosome (Fig. 3i) were occurring frequently during the two years of investigation. The aberrations occurred more frequently in the individuals, collected in 1973. No significant difference in the frequency was proved. Special attention should be payed to the microduplication in section 23/24 (Fig. 3e) (an intensivelly heterochromatic band in one of the homologues). Sometimes the homologous pairing might be disturbed, because of this aberration. The form of the heterochromatic band may be changed or the size increased. Aberration of this type was observed in Ch. thummi by Keyl (1964); the author supposed, that it is due to a duplication, influencing the evolution. In Cr. algarum it was found a microaberration (Fig. 3d), located in the second chro-

Table 2. The frequency of the aberration by Cricotopus algarum

\begin{tabular}{|c|c|c|c|c|c|c|c|c|c|c|}
\hline \multirow{3}{*}{$\begin{array}{l}\text { Chromo- } \\
\text { some }\end{array}$} & \multirow{3}{*}{$\begin{array}{l}\text { Aberration } \\
\text { and } \\
\text { localization }\end{array}$} & \multicolumn{3}{|c|}{1973} & \multicolumn{5}{|c|}{1974} & \multirow[b]{3}{*}{ Fig. } \\
\hline & & \multicolumn{2}{|c|}{$\mathbf{n}$} & \multirow[b]{2}{*}{$\mathrm{n}_{1}$} & \multirow[b]{2}{*}{$\mathrm{p} \pm \mathrm{m}$} & \multicolumn{2}{|c|}{$\mathrm{n}$} & \multirow[b]{2}{*}{$\mathrm{n}_{1}$} & \multirow[b]{2}{*}{$p \pm m$} & \\
\hline & & $\delta \partial^{x}$ & 우우 & & & $\widehat{6} \sigma^{x}$ & 99 & & & \\
\hline I & Hom. Inv. 9/10 & 5 & 29 & - & - & 4 & 29 & 3 & $0,10 \pm 0,06$ & $3 a$ \\
\hline I & Hom. Inv. 23/24 & 5 & 29 & - & - & 4 & 29 & 6 & $0,21 \pm 0,07$ & $3 b$ \\
\hline II & Deletion $10 / 11$ & 5 & 29 & 1 & $0,20 \pm 0,17$ & 4 & 29 & - & - & $3 c$ \\
\hline \multirow[t]{2}{*}{ II } & Duplication & & & & & & & & & \\
\hline & $1 / 2-2 / 3$ & 5 & 29 & - & - & 4 & 29 & 1 & $0,25 \pm 0,02$ & $3 d$ \\
\hline \multirow[t]{2}{*}{ II } & Microduplication & & & & & & & & & \\
\hline & $23 / 24$ & 5 & 29 & 9 & $0,20 \pm 0,07$ & 4 & 29 & 7 & $0,21 \pm 0,07$ & $3 e$ \\
\hline II & Hom. Inv. $22 / 23$ & 5 & 29 & 4 & $0,14 \pm 0,06$ & 4 & 29 & - & - & $3 f$ \\
\hline II & Hom. Inv. $23 / 24$ & 5 & 29 & 3 & $0,10 \pm 0,07$ & 4 & 29 & - & - & $3 \mathrm{~g}$ \\
\hline \multirow[t]{2}{*}{$\Pi$} & Het. Inv. after & & & & & & & & & \\
\hline & $3 / 4$ & 5 & 29 & 10 & $0,29 \pm 0,08$ & 4 & 29 & 6 & $0,18+0,07$ & $3 \mathrm{~h}$ \\
\hline III & Het. Inv. $9 / 10$ & 5 & 29 & 8 & $0,23 \pm 0,07$ & 4 & 29 & 6 & $0,18 \pm 0,07$ & $3 \mathrm{i}$ \\
\hline
\end{tabular}

mosome in section $1 / 2-2 / 3$; it was combined with an incomplete homologous pairing, due to a lack of correspondence in the band structure. Aberrations of the same configuration were found in the species of the genus Glyptotendipes (Miseiko and Minsarrinova 1974).

2. Aberrations, occurring rarely and found only in one of the years of investigation (Table 2).

The repeatedly occurring aberrations have sequence of genes, which determines the structure of the species as a whole unit. The great number of these aberrations means, that the crossing-over in this section of the chromosome is suppressed. The presence of this type of polymorphism is connected with the "stable" polymorphism, which is not influenced by the changes of the abiotic factors.

The second chromosome is more polymorphic than any other and six types of changes were found in it. The aberrations in the right arm of the second chromosome overlap one another. The first and the second couple of chromosomes have 
aberrations in both arms of the chromosome, while the aberrations of the third couple are located near the centromere region of the chromosome. The different stage of development of the active region is an object of peculiar interest as far as the mutability of the second chromosome is concerned. The Balbian ring is dif-

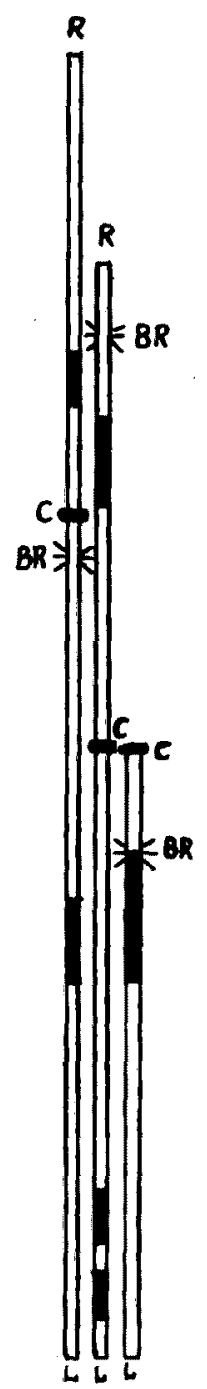

Fig. 4. Schema of the distribution of the aberrations in Cricotopus algarum. ferently manifested even in one and the same gland. Heterozygous Balbian ring and an incomplete homologous pairing can be seen frequently (Fig. $3 \mathrm{j}$ ).

The analysis of the structural changes presented, that the species had comparatively high degree of chromosomal polymorphism. $13,16 \%$ of all studied individuals had homokaryotypes (individuals without aberrations). The presence of heterokaryotypes depends directly on the areal of occurrence of the species (Da Cunha 1955). A population, located about the centre of the areal is more polymorphal than a population, inhabiting the outskirts of the areal (Dobzhansky 1951). The species is in its ecological optimum in the centre and the adaptation to different ecological niches is provided by the high degree of chromosomal polymorphism, which is determined by the place, our country occupies in the species areal.

The changes were found in different combinations: II chromosome, heterozygous deletion+duplication in the same chromosome, section $1 / 2-2 / 3$, microduplication thomozygous inversion, section $22 / 23$, I chromosome, homozygous inversion $9 / 10-10 / 11+$ II chromosome, homozygous inversion, section 23/24 II chromosome, heterozygous inversion $3 / 4+$ III chromosome a complex heterozygous inversion-9/10. The last combination was observed in the individuals, collected in the two years. The presence of different combinations manifests the free panmixia among the individuals of the population. By means of this mechanism of free mating a complete homozygotization of different gene complexes can be achieved, as a result of which the population is divided into a lot of insulated groups. The insulation, which is a result of the process of the cumulation of mutations causes intraspecific divergention (Chetverikov 1926).

The estimated difference in the number of chromosomes of the sexual cells and the somatic cells is interesting. The number of chromosomes in the somatic cells is three, while in the sexual cells it varies between seven and nine. This difference was observed not only between the cells of different individuals, but between the cells of one and the same individual also. Bauer and Beermann (1952) relay 
this difference among the species of the subfamily Orthocladiinae with the presence of " $\mathrm{K}$ " chromosomes in the sexual cells and their behaviour during the mitosis and the meiosis. The elimination of the " $K$ " chromosomes from the somatic cells is defined as "s" elimination and the elimination from the sexual cells as " $\mathrm{K}$ " elimination.

The females predominated in the samples of the two years. The ratio was $3: 1 / \chi^{2}=6,042<\chi^{2}=10,051 /$.

\section{Conclusions}

The results of this investigation can be concluded as follows:

1. The species $\mathrm{Cr}$. algarum can be identified in the larval stage on the basis of data of the karyological analysis.

2. The diploid set of chromosomes was estimated for the first time and salivary-chromosome map was prepared.

3. The presence of a chromocentre in the genus Cricotopus was reported for the first time.

4. The high degree of chromosomal polymorphism is probably in relation with the place our country occupies in the areal of distribution of the species.

5. Different types of aberrations were observed and they were incorporated into two groups:

a. repeatedly oocurring aberrations;

b. aberrations, specific for a certain year.

6. Differences in the numbers of chromosomes in the somatic and in the sexual cells were estimated.

\section{Summary}

The polytene chromosomes of $\mathrm{Cr}$. algarum from the Black Sea coast of Bulgaria were analysed. Salivary-chromosome map of the species was made. The diploid set of chromosomes is $2 n=6$. The first couple is submetacentric, the second-metacentric and the third-acrocentric. The three couples have significant differences in length. The chromosomes are concentrated in chromocentre. A comparatively high degree of chromosomal polymorphism was estimated and it was probably in relation with the distribution of the species. Aberrations, specific for every year and repeatedly occurring aberrations, determining the presence of "stable" polymorphism were found. Differences in the numbers of chromosomes in the somatic and in the sexual cells were reported.

\section{References}

Bauer, H. and Beermann, W. 1952. Der Chromosomencychus der Orthocladinae (Nematocera, Diptera). Zs. Naturforschung 7b:557-563.

Beermann, W. 1952. Chromosomenstructur und Zelldifferenzierung in der Speicheldrüsen von Trichocladius vitripennis. Zs. Naturforsch. $7 \mathrm{~b}: 237-242$.

Chetverikov, S. 1926. About some features of evolution progress in point of view of the con- 
temporary genetics. J. Exp. Biology 2: 33-74 (in Russian).

Chubareva, L. 1974. Chromosomal polymorphism in natural populations of black flies and some other Diptera. Cytology 3: 267-280 (in Russian).

Da Cunha, A. 1955. Chromosomal polymorphism in the Diptera. Adv. in Genetics 7: 93-138.

Dobzhansky, Th. 1951. Genetics and the Origin of Species. 3rd ed. Columbia Univ. Press. New York.

Keyl, H. 1959. Die cytologische Diagnostik der Chironomiden. Bestimmungstabelle für die Gattung Chironomus auf Grund der Speicheldrüsenchromosomen. Arch. f. Hydrb̌iol. 56: $43-57$.

- 1964. Verdopplung des DNS-Gehalts kleiner Chromosomenabschnitte als Faktor der Evolution. Naturwiss. $51: 46-47$.

Lakin, G. 1973. Biometry. Moscow.

Levan, A., Fredga, K. and Sandberg, A. 1964. Nomenclature for centrometric position on chromosomes. Hereditas 52: 201-220.

Michailova, P. 1975. Karyological characteristics of Cricotopus varians staeg, and Cricotopus vitripennis (Diptera, Chironomidae) from the Bulgarian Black Sea coast. Acta Zool. Bulgarica 2: 25-37 (in Bulgarian).

- 1976. Cytotaxonomic diagnostics of species from the genus Cricotopus (Diptera, Chironomidae). Caryologia (in press).

Miseiko, G. and Minsarinova, B. 1974. Karyological structure in natural propulations of two species from the genus Glyptotendipes. Cytology 7 (in Russian).

Valkanov, A. and Michailova, P. 1974. Untersuchungen über der Karyotypus und Chromosomenpolymorphismus bei Thalassomyia frauenfeldi Schiner (Diptera, Chironomidae) von der Bulgarischen Schwarzmeerküste. Bull. de L'Institut de Zoologie et Musee. 40: 5-16. 